Books, videos, cd-roms, dvds and any other relavent items submitted for a review in the bdj should be addressed to:

Mike Grace, Editor, British Dental Journal, 64 Wimpole Street WIG 8YS

\section{The art of the smile: Integrating prosthodontics, orthodontics, periodontics, dental technology and plastic surgery in esthetic dental treatment}

\author{
R. Romano (Ed) \\ UK: Quintessence \\ price $€ 152$, pp 446 \\ ISBN 1850970963
}

In this excellent book, five disciplines: prosthodontics, orthodontics, periodontics, dental technology and plastic surgery are each prefaced by an internationally recognised expert, with material from 20 other contributors and copious references.

The prosthodontics section pleads for dentists to be trained as better scientists, artists and technicians and to liaise with other specialities. Elimination of triangular spaces is explained, as well as full arch restorations with all ceramic crowns, and the importance of bleaching discoloured roots of root filled teeth. A diagram of the Golden Proportion is included, although regrettably my pioneering work is not referenced.

Types of treatment amenable to orthodontics are described next, from aesthetic gingival margins to black triangles and optimum crown lengths. A comprehensive methodology is given for recording and assessing optimal smile factors, while tooth transplantation is covered by Scandinavian experts. Detailed interdisciplinary handling of congenitally missing lateral incisors is followed by considerations for a beautiful smile, including established benchmarks and treatment objectives. Lingual appliances are also extensively described.

We are reminded in the periodontal section that beautiful smiles are lip generated. The importance of achieving harmony between zeniths of free gingival margin and drape of upper lip is stressed, with a good discussion on the psychology of the patient dentist relationship. In dental technology, the latest techniques of layering and segmental build up to influence refractive index and translucency, shade communication and the spectrashade are described. The section on plastic surgery stresses how people convey pleasure and emotion through smiling. Procedures are described to diminish ageing, augment soft tissue and carry out rhinoplasty.

This is an outstanding book supported with excellent quality illustrations and apt text layout. I would definitely recommend it, as it was a great pleasure to read.

E. Levin

\section{Principles of operative dentistry}

\begin{tabular}{l} 
A. J. E. Qualtrough, J. D. Satterthwaite, L. A. Morrow, \\
P. A. Brunton \\
UK: Blackwell \\
price $£ 24.95$, pp 192 \\
ISBN 1405118210 \\
\hline
\end{tabular}

This text seeks to distil the theoretical concepts underpinning operative dentistry in 170 pages. It is written by a team from Manchester and Leeds and is directed at dental students and professionals complementary to dentistry.

A first chapter covers ergonomics, selective aspects of clinical examination, caries and moisture control. It is so brief as to be frankly useless. I am biased, but the theoretical concepts of cariology underpinning operative dentistry cannot be covered in five pages.

A second chapter similarly fails to cover direct restorations in 22 pages. The next chapter on endodontics (30 pages) is well written presenting both principles and technique. This will be useful to dental
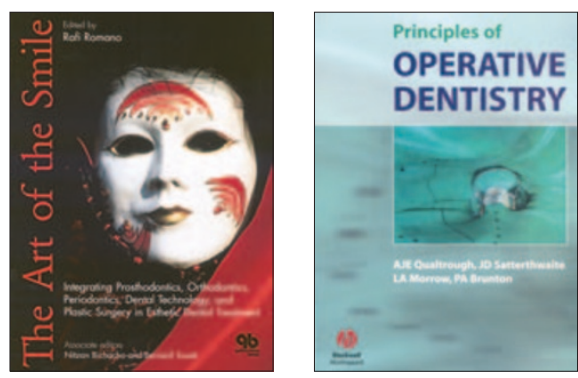

students. A further 24 page endodontic chapter covers aspects of trauma, resorption, perio-endo lesions and restoration of the root filled tooth.

There follow 22 pages on the principles of indirect restoration and I fear the brief text may leave the student bewildered. A further chapter on indirect restorations devotes 22 pages to choice of material, the choice of intra or extra-coronal restorations, the advantages and disadvantages of partial coverage, temporary restoration and impressions, methods of construction of restorations and the problems of short teeth and too little occlusal space. Each topic is just touched upon. Failure and maintenance of restorations is a penultimate chapter, which at five pages, with no illustrations, is totally inadequate.

The last chapter is a discussion of evidence-based dentistry and one wonders why this was not the first chapter. The rest of the text, although referenced, does not follow the evidencebased route since the book does not point out which principles have an evidencebase and which do not.

Perhaps my major problem with this book is the lack of good illustrative material. All pictures are in black and white. Presumably the publishers dictated this format, but it results in a lack-lustre presentation. There are nine foggy extraoral pictures, two of which are tantalisingly reproduced clearly in colour on the cover, and only one intra-oral picture. There are numerous diagrams but many are unhelpful. Some are too small; others have inadequate legends or are confusing or are just wrong. There are no radiographs and this is incredible considering a Professor of Radiology is one of the contributors.

Dental students at Manchester and Leeds should use this book before exams because their teachers wrote it and it will hopefully complement their 'in house' manuals. Apart from the endodontic chapters, I think the rest of the student body should give this book a miss. 
Books, videos, CD-ROMs, DVDs and any other relevant items submitted for a review in the $B D J$ should be addressed to: Kate Maynard, Assistant Editor, British Dental Journal, NPG, 4-6 Crinan Street, London N1 9XW

\section{Manual of}

\section{temporomandibular disorders}

\author{
E. F. Wright \\ UK: Blackwell \\ price $€ 59.50$, pp 354 \\ ISBN 0813807522
}

This is a valuable addition to the library of texts on the subject of aetiology, diagnosis and management of temporomandibular disorders.

Although written from an American viewpoint (such as in the use of specific drug names) this text uses terminology familiar to European readers. In this way it provides a refreshing and up to date review of current concepts of management of patients with such conditions.

In the introduction the author states his objectives as being to fill a void by providing a book that: is written for the 'average' reader; is based on an evidence- based and multidisciplinary approach; teaches differential diagnosis of this condition; and identifies patients who are beyond the scope of most dentists. He goes on to fulfil this ambition.

The 19 chapters are set out in a reader friendly way and include 'Quick Consult' practical information points and 'Focal Points' of factual information. 'Technical Tips' suggest ways of handling some diverse clinical situations and guide the reader towards appreciating the significance of symptoms deriving from different sources.

Chapter 2, which outlines a suggested 'Initial Patient Questionnaire', is comprehensive and valuable, but an example of a Clinical Assessment Form would have been equally instructive.

The author adopts a refreshing and practical assessment of the relative value of investigations and suggests for instance that: "practitioners should image only if there is a reasonable expectation that the additional information will

influence a patient's treatment approach.'

The text explores a wide range of treatment modalities and supports the use of appliance therapy as a substantial part of therapeutic treatment. Although the particular design of some examples are not what we are used to prescribing, the underlying principles are in line with currently accepted theory.

There is a (mostly) useful series of appendices which is downloadable from the internet via www.dentistry.blackwell munksgaard.com/wright which interested readers might find worthwhile to peruse.

The book is well illustrated in colour and will be of interest to those who want to keep up to date with current thoughts on TMD, practitioners who have a special interest in the subject and to all dentists who wish to expand their knowledge.

R. Gray

\section{Implantology in general dental practice}

\section{J. Searson, M. Gough, K. Hemmings UK: Quintessence \\ price $€ 28$, pp 102 \\ ISBN 1850970548}

The authors state that the aim of this book is to "provide general dental practitioners with a concise introduction to dental implantology...' Accordingly, they have produced a compact, straightforward textbook that would be very beneficial to those with limited knowledge of implantology.

Each chapter commences with its aims and expected outcomes and is illustrated with radiographs, colour photographs and diagrams. The first chapter opens with a historical overview and then differentiates the subperiosteal, transosseous and endosseous systems. There is a valuable outline of implant hardware design
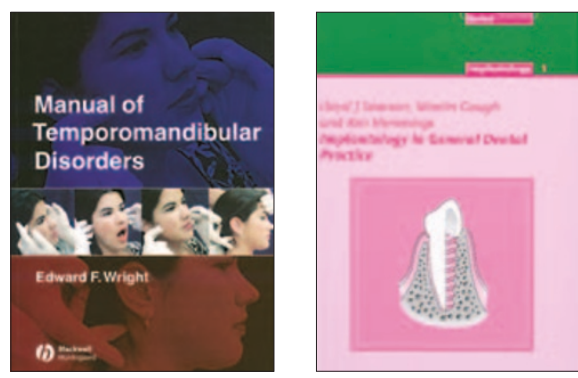

including surface characteristics and implant components. The factors influencing osseointegration are described in detail.

The chapter on case selection discusses the reasons for tooth loss and the options available for tooth replacement. This section seems a little unnecessary for the qualified practitioner.

Patient assessment and treatment planning is reviewed along with advanced imaging techniques. The chapter on surgery details surgical anatomy, the principles of implant positioning and illustrates first and second stage surgery. The prosthodontic aspects of implantology including impressions, occlusal registration and temporisation are summarised and the implant alternatives for partial replacement and edentulous cases outlined. There is a chapter on advanced cases including bone grafts, guided tissue regeneration and maxillofacial prosthodontics. Chapter seven covers the common complications of implant treatment.

Implantology can be very confusing for the uninitiated. All too often textbooks can be overly complicated with insufficient information on the basics. The strength of this book lies in its succinct clarification of implantology. It concentrates on the clinical considerations, omitting extensive detail, thereby providing an excellent synopsis of the subject. This book will answer many of your implant related questions that you have always wanted to ask but never dared!

G. Ainsworth 